\title{
Organic CuTCNQ integrated in complementary metal oxide semiconductor copper back end-of-line for nonvolatile memories
}

\author{
R. Müller, ${ }^{\text {a) }}$ S. De Jonge, K. Myny, D. J. Wouters, J. Genoe, and P. Heremans ${ }^{\text {b) }}$ \\ IMEC v.z.w., Kapeldreef 75, 3001 Leuven, Belgium
}

(Received 8 June 2006; accepted 9 October 2006; published online 27 November 2006)

\begin{abstract}
Nanowires of the organometallic semiconductor CuTCNQ were grown from TCNQ vapor in $250 \mathrm{~nm}$ diameter vias of a $\mathrm{Cu}$ back end-of-line process. Corresponding prototypes of cross-point $\mathrm{Cu} / \mathrm{CuTCNQ}$ nanowire/Al memories exhibited nonvolatile bistable conductive switching for several ten write-erase cycles with switching currents below $10 \mu \mathrm{A}$ and current densities 1000 times higher than for large-area devices. Scaling of memory elements was also investigated. (C) 2006 American Institute of Physics. [DOI: 10.1063/1.2388883]
\end{abstract}

Downscaling of actual memory technology [dynamic random access memory (RAM), Flash, ferroelectric RAM, magnetoresistive RAM] becomes more and more challenging due to physical limitations and increasing processing complexity. ${ }^{1}$ Use of resistive-switching materials (resistive RAM,${ }^{2}$ oxide resistive RAM, ${ }^{3}$ phase change memory, ${ }^{4}$ programmable metallization cell, ${ }^{5}$ and nanobridge ${ }^{6}$ ) combined with nanotechnology may be a solution for further scaling, e.g., by incorporating resistive-switching nanowires (NWs) as memory elements in interconnect via structures. Thereto, the controlled incorporation of suitable NWs or nanocrystals in predefined (via) area's is required.

Organic semiconductors ${ }^{7-17}$ are currently investigated as an alternative to inorganic (metal-oxide) resistive-switching material for future memory generations. CuTCNQ and AgTCNQ (TCNQ=7, 7, 8, 8-tetracyano-p-quinodimethane) are two organometallic semiconductors exhibiting bistable reproducible and nanosecond electrical resistive switching (with $M=\mathrm{Ag}$ or $\mathrm{Cu}$ and $0<x \leqslant n):{ }^{7,13,18-27}$

$$
\underset{\text { off state }}{\left[M^{+} \mathrm{TCNQ}_{n}^{-}\right.} \stackrel{\text { voltage }}{\rightleftharpoons} M_{x}^{0}+\underset{\text { on state }}{\mathrm{TCNQ}_{x}^{0}+\left[M^{+} \mathrm{TCNQ}^{-}\right]_{n-x} .}
$$

Although the exact switching mechanism has not yet been established, in situ Raman spectroscopic measurements, performed through a thin transparent chromium layer as top contact, gave strong evidence for the solid-state equilibrium [Eq. (1)] in the case of CuTCNQ. In fact, Kamitsos et al. ${ }^{28}$ have shown by this technique that (i) the initial film is essentially $\mathrm{Cu}^{+} \mathrm{TCNQ}^{-}$; (ii) after switching to the $\mathrm{ON}$ state, neutral TCNQ is present in the system and the amount of $\mathrm{Cu}^{+} \mathrm{TCNQ}^{-}$decreases; (iii) approximately $10 \mathrm{~mol} \%$ of conversion is needed to reach the low impedance ON state; and (iv) the amount of neutral TCNQ produced increases with the time of application of the electric field. These results clearly confirm the importance of the organic memory material $M^{+} \mathrm{TCNQ}^{-}$in the switching process. This is further corroborated by the fact that conductive switching does not only occur with aluminum top and copper or silver bottom contacts, $7,13,18-25$ but also with chromium top and copper bottom electrodes, ${ }^{28}$ between two titane/gold contacts $^{21}$ and even in horizontal devices between two (chemically unreac-

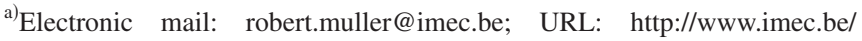
NosceMemorias/

${ }^{b)}$ Also at the Department of Electrical Engineering, Katholieke Universiteit Leuven, Kasteelpark Arenberg 10, B-3001 Leuven, Belgium.
}

tive) gold contacts separated by channels of several hundred nanometers ${ }^{26}$ or more than $20 \mu \mathrm{m}$ width. ${ }^{29}$

In addition to their good resistive-switching properties, CuTCNQ and AgTCNQ are advantageous to most other organic memory materials since they can be "self-assembled" on the corresponding metal by a spontaneous chemical reaction with TCNQ in solution ${ }^{7,18,20,24,27}$ or with TCNQ gas. ${ }^{13,21-23,25,26,30}$ This last method is very promising for nanoelectronic memory devices since NWs of the corresponding semiconductors are formed. Resistive switching of single AgTCNQ NWs in horizontal devices, prepared by e-beam patterning, has already been shown by Fan et al. ${ }^{13,21}$ Recently our group presented results on electrical switching of CuTCNQ NWs grown on pad-size devices and on top of $\mathrm{Cu}$ filled vias (250 nm diameter) on a back end-of-line (BEOL) wafer. ${ }^{25}$ In this letter we extend the method to the growth of CuTCNQ NWs selectively inside $250 \mathrm{~nm}$ diameter vias of a $\mathrm{Cu}$ BEOL process, resulting in a higher control of the growth location. This constitutes an important progress to the state of the art organic memory material incorporation in vias directly on a $\mathrm{Cu} \mathrm{BEOL}$.

CuTCNQ NWs were grown on $\mathrm{Cu}$ BEOL test structures (Fig. 1) with $250 \mathrm{~nm}$ diameter vias (500 nm height) according to a procedure similar to that reported for the preparation of AgTCNQ NWs. ${ }^{22}$ The mechanism of the corresponding growth reaction, consuming $\mathrm{Cu}$ metal from the bottom contact, should imply diffusion of $\mathrm{Cu}^{+}$ions inside the memory material by analogy with the mechanism published for the growth of AgTCNQ by successive vacuum evaporation of Ag and TCNQ films. ${ }^{31}$ CuTCNQ NWs prepared by this method consist of CuTCNQ phase I (Ref. 32) as shown by $\mathrm{x}$-ray diffraction ${ }^{30}$ and infrared spectroscopy. ${ }^{33}$

By the template growth of CuTCNQ inside vias, the diameter of the NW is limited by the via [Figs. 2(a) and 2(b)]. Since previous experiments allowed us to grow CuTCNQ NWs with diameter and tips down to, respectively, 80 and $22 \mathrm{~nm}$ - in agreement with Refs. 23 and 26-it is highly likely that this template growth method can also be applied for future technology nodes ( 45 and $32 \mathrm{~nm}$ and beyond). To allow electrical contact between the $\mathrm{Cu}$ bottom electrode and the bonding pads, the connecting via structures were covered by a thin layer of unreactive metal $(250 \mathrm{~nm}$ thick $\mathrm{Au})$ before CuTCNQ growth. The Al top contacts (100 nm thickness) were vapor deposited and lithographically patterned [Fig. 2(c)]. Electrical measurements were performed at ambient conditions with an Agilent 4156C precision semiconductor 


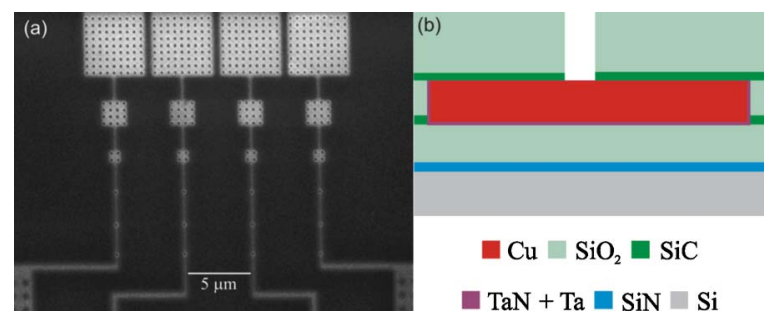

FIG. 1. (Color online) Test structures for integration in the CMOS back end-of-line wafer, consisting of open vias on top of $\mathrm{Cu}$ metal 1 structures: (a) top view [scanning electron microscopy (SEM)] and (b) cross section (schematic).

parameter analyzer, using a triangular staircase signal (typically from +7 to $-7 \mathrm{~V}$ and back, with $0.05 \mathrm{~V}$ steps). During all experiments the memory elements were placed in series with a load resistor $(\mathrm{R})$. Such a resistor, often used in studies of organic and inorganic resistive-switching memory elements, ${ }^{5,34-37}$ was required to prevent the memory against current overload resulting in a permanent on state. The optimal value for a given memory element was experimentally determined by performing $I-V$ experiments with decreasing R (available resistors: 1000, 470, 220, 100, 47, 22, 10, 4.7, 2.2 and $1 \mathrm{k} \Omega$ ) until the memory switched in a reliable way to the on state and could still be switched off. In general, the value had to be increased when the effective junction area of the memory element was decreased. Therefore the load resistor also had to be changed between measurements of single via memory elements and arrays of memory elements [Fig. 2(c)]. Due to the presence of the load resistor, the effective voltage across the memory was different from the voltage applied by the parameter analyzer. For this reason both the current and the voltage across the memory element were recorded and plotted in the $I-V$ graphs. This representation exhibits zones of negative differential resistance (NDR) in which a decrease of voltage results in an increase of current, and an increase of voltage in a decrease of current. $^{34-37}$

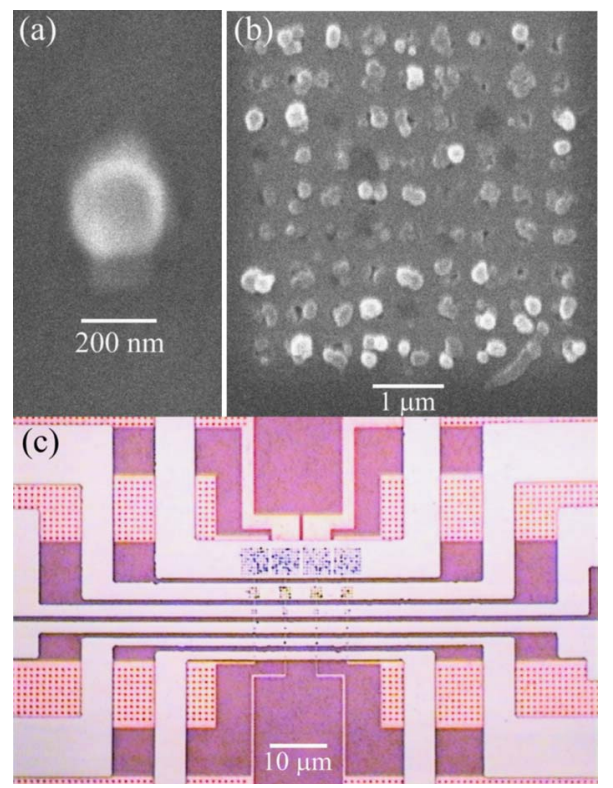

FIG. 2. (Color online) SEM micrographs of CuTCNQ nanowires grown (a) in a single $250 \mathrm{~nm}$ via, (b) inside 81 vias of an ensemble memory element, and (c) optical micrograph of the structure after deposition and pattering of Al top contacts.

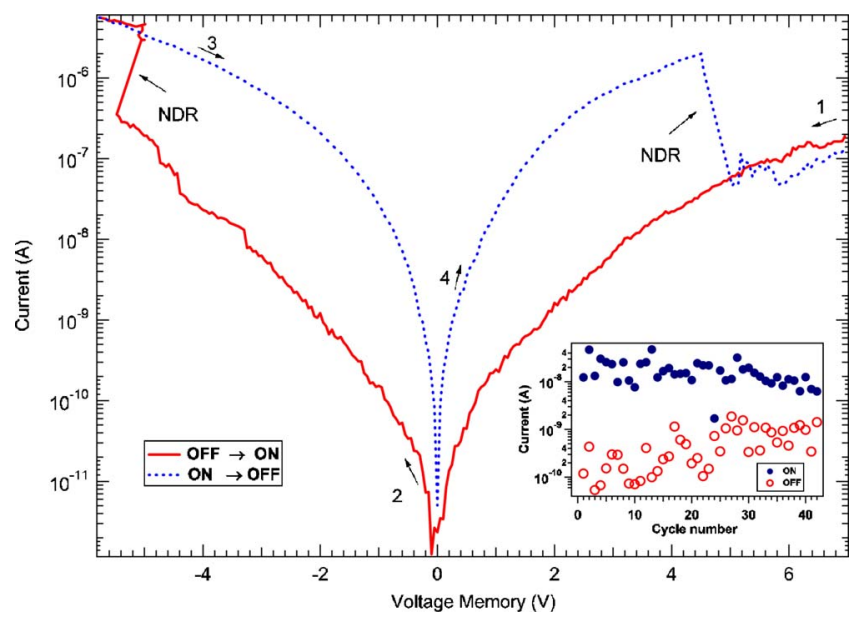

FIG. 3. (Color online) Typical $\log |I|-V$ curve of a Cu/CuTCNQ NW/Al memory grown in $250 \mathrm{~nm}$ diameter via (load resistor $R=220 \mathrm{k} \Omega$, voltage scan $+7 \rightarrow-7 \rightarrow+7 \mathrm{~V})$. The inset shows on and off currents recorded at $-1 \mathrm{~V}$ for several ten cycles.

Current-voltage curves of CuTCNQ memories in BEOL vias exhibited a similar shape as observed for pad-size devices. ${ }^{24,25,38,39}$ The memories were as grown in the off state. At about -5 to $-6 \mathrm{~V}$ applied to the $\mathrm{Al}$ top electrode, they switched to a high conductive on state, in which they remained until about $+5 \mathrm{~V}$ was applied to switch them off again (Fig. 3). Single-via memory elements exhibited several tens of write/erase cycles with on/off current ratios between 10 and 100 (Fig. 3 inset). It should also be mentioned that a device programed to the on state does not spontaneously return to the off state when the voltage sweep passed through $0 \mathrm{~V}$ (Fig. 3). This is a clear indication that the device operates as memory and not as threshold switch. Preliminary experiments performed by programming the memory to the on state (voltage sweep from 0 to $-7 \mathrm{~V}$ and back) and recording the current during several read cycles (from -3.5 to $4.5 \mathrm{~V}$ and back) within 5 min did not show any decrease in read current. Since previous measurements realized on large-area $\mathrm{Cu} / \mathrm{CuTCNQ} / \mathrm{Al}$ memories ${ }^{24}$ showed data retention of over more than $60 \mathrm{~h},{ }^{40}$ this kind of organic resistive-switching device is promising for nonvolatile memory applications.

Maximum switching current of a single $\mathrm{Cu} / \mathrm{CuTCNQ}$ NW/Al memory is between 1 and $10 \mu \mathrm{A}$ for $500 \mathrm{~nm}$ thickness of CuTCNQ. This compares favorably to the large switching currents of a few hundred microamperes to several milliamperes for other technologies. ${ }^{3-6}$

On state current densities $\left(10^{7} \mathrm{~A} / \mathrm{m}^{2}\right)$ for single-via memory elements are $10^{3}$ times higher than those of pad-size devices. ${ }^{24,25}$ This increase in conductivity should be assigned to uniform filling of the vias, avoiding empty spaces between microcrystals and/or overlapping of NWs as in pad-size devices, and leading to increased contact areas with both bottom and top electrodes. According to a theoretical study, ${ }^{41}$ the low electrical resistivity of CuTCNQ after switching to its on state results from the formation of conductive $\mathrm{Cu}$ stakes in which electrons can easily migrate. The singlecrystal nature of each CuTCNQ nanowire, with high conductivity $\mathrm{Cu}$ paths in the crystal along the wire axis, may explain the high current density that we can achieve in the on state. Compared to conductive switching of single AgTCNQ NW in a horizontal device (about $220 \mathrm{~nm}$ diameter and $0.73 \mu \mathrm{m}$ length ${ }^{13}$ ), our memories based on CuTCNQ NWs in $250 \mathrm{~nm}$ 


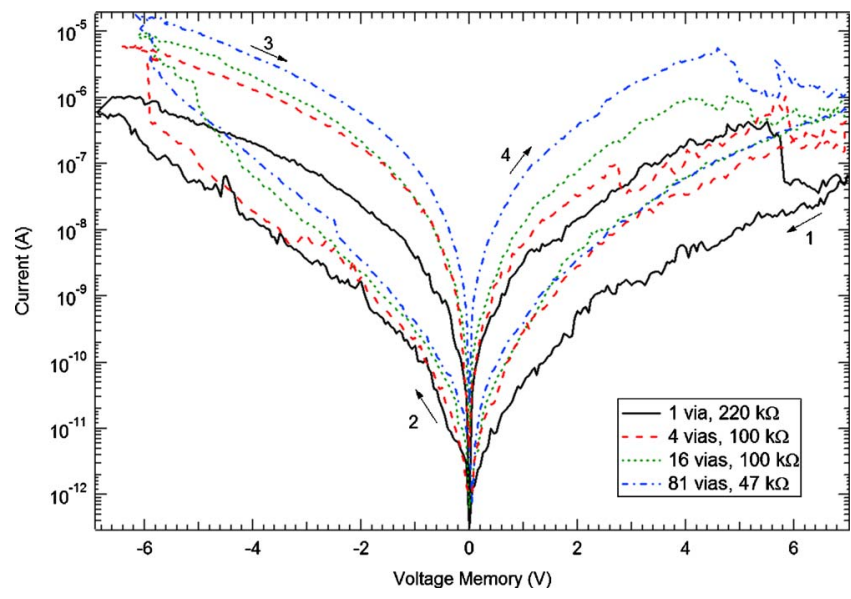

FIG. 4. (Color online) $\log |I|-V$ curves recorded for a single $250 \mathrm{~nm}$ via CuTCNQ memory and ensembles of 4,16 , and 81 memories (voltage scan: $+7 \rightarrow-7 \rightarrow+7 \mathrm{~V}$, variable load resistor).

diameter and $500 \mathrm{~nm}$ high vias require a lower switching voltage (about $6 \mathrm{~V}$ compared to about $7.4 \mathrm{~V}$ ) and exhibit higher switching currents [microamperes instead of about $0.1 \mu \mathrm{A}$ for AgTCNQ (Ref. 13). Whereas the difference in switching voltage seems to depend on material thickness (thin AgTCNQ films can be switched below $0.2 \mathrm{~V},{ }^{21}$ ), the difference in current intensity might be related to experimental parameters such as the load resistor $\mathrm{R}(220 \mathrm{k} \Omega$ for a single CuTCNQ memory element and $22 \mathrm{M} \Omega$ for the AgTCNQ NW ${ }^{13}$ ) and the orientation of the metal contacts with respect to the NW. In fact, it can be expected that the current transport via conductive channels (as, for example, the $\mathrm{Cu}$ stakes ${ }^{41}$ ) is more efficient when the electrical contacts are placed at both ends of a NW segment than when they are placed laterally on the same side of the nanowire.

Further $I-V$ measurements performed on ensembles of $\mathrm{Cu} / \mathrm{CuTCNQ}$ NW/Al cross-point cells (Fig. 4) show scaling of the on state current with the number of vias forming the memory elements. This indicates that for the memory ensembles, and thus also for pad-size devices, the rise of current with the area is related to an increase in number of the conductive channels, which might be the before mentioned $\mathrm{Cu}$ stakes. ${ }^{41}$ However, probably due to incomplete CuTCNQ growth in some vias [Fig. 2(b)] resulting in partial (or even absence of) electrical contact with the Al top electrode, no direct linear relationship could be observed between the current and the number of vias.

In summary, prototypes of $\mathrm{Cu} / \mathrm{CuTCNQ} / \mathrm{Al}$ memories prepared by growing CuTCNQ nanowires in $250 \mathrm{~nm}$ diameter vias exhibit good conductive switching performance and scalability of the on and off currents. Since CuTCNQ nanowires can be grown with even smaller diameter, these results are very encouraging for future scaling studies targeting the 45 and $32 \mathrm{~nm}$ nodes, and below, of the international semiconductor roadmap.

This research was performed within the framework of the NOSCE MEMORIAS project of the European Commission (FP6-507934).

${ }^{1}$ R. Bez and A. Pirovano, Mater. Sci. Semicond. Process. 7, 349 (2004). ${ }^{2}$ W. W. Zhuang, W. Pan, B. D. Ulrich, J. J. Lee, L. Strecker, A. Burmaster, D. R. Evans, S. T. Hsu, M. Tajiri, A. Shimaoka, K. Inoue, T. Naka, N. Waya, K. Sakiyama, Y. Wang, S. Q. Liu, N. J. Wu, and A. Ignatiev, Tech. Dig. - Int. Electron Devices Meet. 2002, 193.
${ }^{3}$ I. G. Baek, M. S. Lee, S. Seo, M. J. Lee, D. H. Seo, D. S. Suh, J. C. Park, S. O. Park, H. S. Kim, I. K. Yoo, U. I. Ching, and J. T. Moon, Tech. Dig. - Int. Electron Devices Meet. 2004, 587.

${ }^{4}$ S. J. Ahn, Y. J. Song, C. W. Jeong, J. M. Shin, Y. Fai, Y. N. Hwang, S. H. Lee, K. C. Ryoo, S. Y. Lee, J. H. Park, H. Horii, Y. H. Ha, J. H. Yi, B. H. Kuh, G. H. Koh, G. T. Jeong, H. S. Jeong, K. Kim, and B. I. Ryu, Tech. Dig. - Int. Electron Devices Meet. 2004, 907.

${ }^{5}$ M. Kozicki, M. Park, and M. Mitkova, IEEE Trans. Nanotechnol. 4, 331 (2005).

${ }^{6}$ S. Kaeriyama, T. Sakamoto, H. Sunamura, M. Mizuno, H. Kawaura, T. Hasegawa, K. Terabe, T. Nakayama, and M. Aono, IEEE J. Solid-State Circuits 40, 168 (2005).

${ }^{7}$ R. S. Potember, T. O. Poehler, and D. O. Cowan, Appl. Phys. Lett. 34, 405 (1979).

${ }^{8}$ D. Ma, M. Aguiar, J. A. Freire, and I. A. Hummelgen, Adv. Mater. (Weinheim, Ger.) 12, 1063 (2000).

${ }^{9}$ S. Moller, S. R. Forrest, C. Perlov, W. Jackson, and C. Taussig, J. Appl. Phys. 94, 7811 (2003).

${ }^{10}$ A. Bandyopadhyay and A. J. Pal, Appl. Phys. Lett. 82, 1215 (2003).

${ }^{11}$ Y. Yang, L. P. Ma, and J. H. Wu, MRS Bull. 29, 833 (2004).

${ }^{12}$ L. P. Ma, Q. F. Xu, and Y. Yang, Appl. Phys. Lett. 84, 4908 (2004).

${ }^{13}$ Z. Fan, X. Mo, C. Lou, Y. Yao, D. Wang, G. Chen, and J. G. Lu, IEEE Trans. Nanotechnol. 4, 238 (2005).

${ }^{14}$ J. Y. Ouyang, C. W. Chu, D. Sieves, and Y. Yang, Appl. Phys. Lett. 86, 123507 (2005).

${ }^{15}$ L. D. Bozano, B. W. Kean, M. Beinhoff, K. R. Carter, P. M. Rice, and J. C. Scott, Adv. Funct. Mater. 15, 1933 (2005).

${ }^{16}$ R. J. Tseng, J. X. Huang, J. Ouyang, R. B. Kaner, and Y. Yang, Nano Lett. 5, 1077 (2005).

${ }^{17}$ A. Pirovano, R. Sotgiu, S. Conoci, S. Petralia, and F. Buonocore, SolidState Electron. 49, 1820 (2005).

${ }^{18}$ C. Sato, S. Wakamatsu, K. Tadokoro, and K. Ishii, J. Appl. Phys. 68, 6535 (1990).

${ }^{19}$ H. J. Gao, Z. Q. Xue, and S. J. Pang, J. Phys. D 29, 1868 (1996).

${ }^{20}$ S.-G. Liu, Y.-Q. Liu, P.-J. Wu, and D.-B. Zhu, Chem. Mater. 8, 2779 (1996).

${ }^{21}$ Z. Fan, X. Mo, G. Chen, and J. Lu, Rev. Adv. Mater. Sci. 5, 72 (2003).

${ }^{22}$ C. Ye, G. Gao, X. Mo, F. Fang, X. Xing, G. Chen, and D. Sun, Chin. Phys. Lett. 21, 1787 (2004).

${ }^{23}$ H. Liu, Q. Zhao, Y. Li, Y. Liu, F. Lu, J. Zhuang, S. Wang, L. Jiang, D. Zhu, D. Yu, and L. Chi, J. Am. Chem. Soc. 127, 1120 (2005).

${ }^{24}$ R. Müller, J. Genoe, and P. Heremans, Proceedings of the First International Conference on Memory Technology and Design, Giens, France, 21-24 May 2005 (unpublished), pp. 181-183.

${ }^{25}$ R. Müller, S. De Jonge, K. Myny, D. J. Wouters, J. Genoe, and P. Heremans, Solid-State Electron. 50, 601 (2006).

${ }^{26}$ K. Xiao, I. Ivanov, A. Puretzky, Z. Liu, and D. Geohegan, Adv. Mater. (Weinheim, Ger.) 18, 2184 (2006).

${ }^{27}$ Y. Liu, Z. Ji, Q. Tang, L. Jiang, H. Li, M. He, W. Hu, D. Zhang, L. Jiang, X. Wang, C. Wang, Y. Liu, and D. Zhu, Adv. Mater. (Weinheim, Ger.) 17, $2953(2005)$

${ }^{28}$ E. Kamitsos, C. Tzinis, and W. Risen, Jr., Solid State Commun. 42, 561 (1982).

${ }^{29}$ Supporting information for, ${ }^{28}$ URL http://www.wiley-vch.de/contents/ jc_2089/2005/c0809_s.pdf

${ }^{30}$ K. Xiao, J. Tao, Z. Pan, I. Ivanov, A. Puretzky, Z. Liu, S. Pennycook, and D. Geohegan, Proceedings of the MRS Spring Meeting, San Francisco, 2006 (unpublished).

${ }^{31}$ P. Liu, Y. Jiang, H. Xie, F. Guo, and J. Li, Jpn. J. Appl. Phys., Part 2 44, L494 (2005).

${ }^{32}$ R. A. Heintz, H. Zhao, X. Ouyang, G. Grandinetti, J. Cowen, and K. R. Dunbar, Inorg. Chem. 38, 144 (1999).

${ }^{33}$ Supporting information for, Ref. 24 URL http://pubs3.acs.org/acs/journals/ supporting_information.page\%?in_manuscript $=$ ja0438359

${ }^{34}$ J. Krieger, S. Trubin, S. Vaschenko, and N. Yudanov, Synth. Met. 122, 199 (2001).

${ }^{35}$ S.-G. Liu, Y.-Q. Liu, and D.-B. Zhu, Thin Solid Films 280, 271 (1996).

${ }^{36}$ S. Sun, P. Wu, and D. Zhu, Thin Solid Films 301, 192 (1997).

${ }^{37}$ K. Wang, Z. Xue, M. Ouyang, and H. Zhang, Solid State Commun. 96, 481 (1995).

${ }^{38}$ T. Omayada, H. Tanaka, K. Matsushige, H. Sasabe, and C. Adachi, Appl. Phys. Lett. 83, 1252 (2003).

${ }^{39}$ R. Müller, J. Genoe, and P. Heremans, Appl. Phys. Lett. 88, 242105 (2006).

${ }^{40}$ R. Müller, J. Genoe, and P. Heremans (unpublished).

${ }^{41}$ Z. Gu, H. Wu, Y. Wei, and J. Liu, J. Phys. Chem. 97, 2543 (1993). 